\title{
In Memory of Chong-Sun Kim
}

\author{
Seung-Ha Oh \\ Department of Otorhinolaryngology, Seoul National University Hospital, Seoul National University College of Medicine, Seoul, Korea
}

Department of Otorhinolaryngology, Seoul National University College of Medicine in Seoul, Korea, has announced the passing of Professor Chong-Sun Kim, M.D., Ph.D. He was born in Seoul, Korea on August 29, 1942 (Fig. 1). After he graduated from Seoul National University in 1966 and finished resident training at Seoul National University Hospital, he started his carrier as a teacher at Seoul National University. He received his Ph.D. degree in 1972 and undertook a post-doctoral fellowship at the University of Minnesota from 1976 to 1978 under the supervision of Prof. Michael Paparella. He finished his skull base surgical training in Prof. Ugo Fisch's Clinic in Zurich in 1981.

He was appointed the chairman of the Department of Otorhinolaryngology-Head and Neck Surgery of Seoul National University in 1992 and served until 1996. In 1990, he founded the Korean Otological Society and served as the 1st President until 1994. In 1997, he was appointed the 10th Chairman of the Board of Directors of the Korean Society of Otorhinolaryngology-Head and Neck Surgery (ORL-HNS) and served until 1999. Also, from

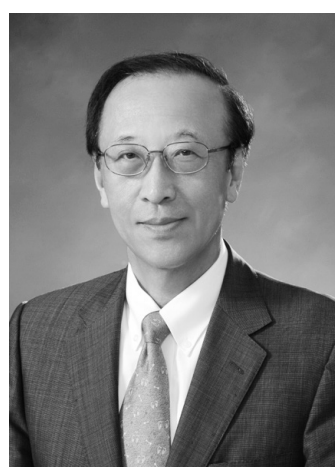

Fig. 1. Professor Chong-Sun Kim (19422019). Professor Chong-Sun Kim who was the Founding President of Korean Otological Society (1990-1994) and the President of International Federation of ORL Societies (2013-2017).

- Received January 21, 2019

Accepted January 21, 2019

- Corresponding author: Seung-Ha Oh

Department of Otorhinolaryngology, Seoul National University Hospital, Seoul National University College of Medicine, 101 Daehak-ro, Jongno-gu, Seoul 03080, Korea

Tel: +82-2-2072-2442, Fax: +82-2-745-2387

E-mail:shaoh@snu.ac.kr
1997 to 1998, he was appointed the 3rd President of the Korean Skull Base Society.

Chong-Sun Kim had been an extremely active participant at international meetings, workshops, and conferences, in many of these as invited speaker and faculty member. He had organized the 7th Korean-Japan Joint Meeting of ORL-HNS in 1998, the 2nd Asia-Pacific Symposium on Cochlear Implants \& Related Sciences (APSCI) in 1999, the 25th Politzer Society Meeting in 2005, the Collegium Oto-Rhino-Laryngologicum Amicitiae Sacrum (CORLAS) meeting in 2007, and the 20th International Federation of ORL Societies (IFOS) World Congress in 2013. He also served as an officer in IFOS; Executive Board Member (2002-2005), Regional Secretary (2005-2009), Vice-President (2009-2013), and President (2013-2017). The manner in which Professor Kim prepared these scientific programs was extremely sincere and perfect, and we always learned an outstanding standard to ensure the success of meetings.

He was a true teacher and scientist. His whole life was dedicated to education and research under strict discipline. Especially, he raised many young otologic surgeons by introducing the domestic temporal bone dissection course that has been lasted more than 25 years. However, his warm smile and fair-minded encouragement for the young generation were always balanced in his mind. He himself was a very competent surgeon. He started cochlear implantation surgery in Korea in 1988 and gave hope of hearing in more than 1,000 deaf patients.

Chong-Sun Kim passed away on December 29, 2019. He left behind his beloved wife, Pauline, two sons (Young Ho and Young Chul), extended family, and many friends. His eldest son, Prof. Young Ho Kim is currently working as an otologic surgeon in the same university and department.

Copyright (c) 2020 by Korean Society of Otorhinolaryngology-Head and Neck Surgery.

This is an open-access article distributed under the terms of the Creative Commons Attribution Non-Commercial License (https://creativecommons.org/licenses/by-nc/4.0)

which permits unrestricted non-commercial use, distribution, and reproduction in any medium, provided the original work is properly cited. 